\section{Autoantikörper gegen $\alpha$-Fodrin}

\section{W. Stöcker}

Euroimmun Medizinische Labordiagnostika AG, Lübeck, Deutschland

\section{Synonym(e) Anti- $\alpha$-Fodrin-Antikörper}

Englischer Begriff antibodies to $\alpha$-fodrin

Definition Autoantikörper gegen $\alpha$-Fodrin reagieren mit dem $120 \mathrm{kDa}$ großen Fragment eines Moleküls, das im Zusammenhang mit apoptotischen Prozessen beim Abbau von Zytoskelettstrukturen entsteht. Es wurde eine Assoziation mit dem Sjögren-Syndrom beschrieben.

Funktion - Pathophysiologie Fodrin ist einer der Hauptbestandteile des Zytoskeletts mit einer Heterodimerstruktur. Die $\alpha$-Untereinheit bindet unter anderem Actin, Calmodulin und CD45. Man vermutet, dass eine Infiltration von Lymphozyten in das Drüsengewebe zu einer verminderten Sekretion und zu apoptotischen Prozessen führt. Während das native Protein nicht (auto-)immunogen ist, entsteht beim Zellabbau das 120 kDa große Fragment, das möglicherweise die Autoantikörper induziert.

\section{Untersuchungsmaterial Serum.}

Probenstabilität Autoantikörper sind bei $+4{ }^{\circ} \mathrm{C}$ bis $\mathrm{zu}$ 2 Wochen lang beständig, bei $-20^{\circ} \mathrm{C}$ über Monate und Jahre hinweg
Analytik Bei der Immunantwort gegen $\alpha$-Fodrin findet man in der Regel sowohl IgG- als auch IgA-Antikörper. Sie lassen sich durch $>$ Enzymimmunoassay, $>$ Immunblot oder Immunpräzipitation nachweisen. Das entsprechende Antigen gewinnt man durch chromatografische Aufreinigung ( $>$ Chromatographie) oder seit einiger Zeit auch durch rekombinante Expression in geeigneten Vektoren.

\section{Referenzbereich - Erwachsene Negativ.}

Referenzbereich - Kinder Negativ.

Indikation Im Jahr 1997 beschrieben Haneji et al. eine Assoziation von Autoantikörpern gegen $\alpha$-Fodrin mit dem Sjögren-Syndrom. In nachfolgenden Studien wurden bei 25 bis über $90 \%$ der Patienten Autoantikörper gegen $\alpha$-Fodrin gefunden.

Auch bei der seltenen Durchblutungsstörung Moya-MoyaSyndrom sollen Autoantikörper gegen $\alpha$-Fodrin vorkommen.

Diagnostische Wertigkeit Die in Studien durchschnittlich erzielte diagnostische Sensitivität von Anti- $\alpha$-Fodrin-Antikörpern für das Sjögren-Syndrom beträgt 39,3\% bei einer diagnostischen Spezifität von $83 \%$.

\section{Literatur}

Haneji N, Nakamura T, Takio K et al (1997) Identification of alphafodrin as a candidate autoantigen in primary Sjogren's syndrome. Science 276:604-607

Ulbricht KU, Schmidt RE, Witte T (2003) Antibodies against alphafodrin in Sjogren's syndrome. Autoimmun Rev 2:109-113 